\title{
Literatura, cultura e outras artes: percursos críticos, interpretativos e metodológicos
}

A discussão sobre a relação entre a literatura e outras artes tem uma longa tradição, que inicialmente destaca o debate entre as artes irmãs e inclui, entre seus textos mais importantes, a célebre missiva de Horácio Ars Poetica (c. 14-13 a.C.), e Laokoon (1766), de Lessing. Essa tradição foi acolhida nos estudos de literatura comparada desde a fundação da disciplina, embora não sem reservas, como expõe Henry H. H. Remak em "Literatura comparada: definição e função". Remak, em seu ensaio de 1961, defende o conceito de literatura comparada como disciplina que abriga não apenas "a comparação de uma literatura com outra ou outras", mas também "a comparação da literatura com outras esferas da expressão humana", como as artes (Remak, 1994, p. 175).

Em 1995, o evento "Interarts Studies: New Perspectives", realizado na Universidade de Lund, inaugura um novo termo para identificar o discurso sobre as inter-relações entre as artes. A criação do termo "Estudos Interartes" representaria, assim, uma mudança de ponto de vista em direção a uma abordagem interdisciplinar das artes em um campo de estudos em que a literatura não é mais a referência dominante (Pedroso Júnior, 2012; Clüver, 2001, 2006).

Com as transformações recentes nas práticas culturais, especialmente com o surgimento de novas mídias, o discurso interartes passa a interessar-se por fenômenos contemporâneos que envolvem "textos" (agora entendidos em acepção mais ampla na perspectiva semiótica) nem sempre considerados artísticos no sentido tradicional, além de textos híbridos que encontram dificuldades de serem situados no sistema acadêmico: a história em quadrinhos, a instalação e o livro de artista, por exemplo (Clüver, 2006). Os Estudos Interartes seriam, desse modo, absorvidos pelo estudo das inter-relações e interações entre as várias mídias, entre elas a palavra e a imagem. A partir do conceito de intermidialidade, então, as investigações sobre as mídias e seus objetos, sobre as relações entre as artes tradicionais, e as relações entre estas e as novas mídias como formas de arte encontrariam espaço nos "Estudos da Intermidialidade" ou "Estudos Intermidiáticos". 
Como observa Claus Clüver (2001, p. 359), “o século XX foi marcado por um alto grau de interactividade entre as artes”. Esta tendência da prática artística, ainda visível atualmente, está centrada nas formas mistas, isto é, em criações que configuram interação ou a reunião de diferentes mídias. 0 caráter predominantemente misto das artes contemporâneas pode ter impulsionado o debate sobre a intermidialidade; contudo, como argumenta Clüver, o fenômeno intermidiático não é recente na produção literária: “os escritores sempre tiveram tendência para atravessar não apenas as fronteiras nacionais e linguísticas, mas ainda as que separam as artes" (2001, p. 359).

O número 51 da revista Letras explora a relação entre a literatura e outras artes ou mídias, e reflete a diversidade temática e metodológica na abordagem de diferentes escritas que atravessam as fronteiras que separam as artes em diferentes contextos. Um dos casos notáveis que desafia as fronteiras entre as artes é a obra do poeta, pintor e gravurista William Blake. Em "William Blake and the Emergence of Romantic Media Studies", Burkett (2015, p. 443) mostra que, apesar de a "arte compósita" de Blake ter uma rica tradição crítica de análise materialista, a discussão da complexa rede multimídia de elementos gráficos, pictóricos, textuais e materiais de seus livros está longe de se esgotar. O dossiê "William Blake e sua poética interartes" do presente número da revista Letras reforça o argumento de Burkett ao estudar a obra do artista inglês como complexo de relações entre diferentes formas artísticas.

No primeiro artigo do dossiê, "Livros iluminados digitais: autógrafo e reprodução em The William Blake Archive", Manuel Portela examina, levando em consideração a codificação bibliográfica da obra literária, a lógica representacional e analítica do projeto de recodificação eletrônica The William Blake Archive, um arquivo público que procura reunir os exemplares das edições autógrafas dos livros iluminados de Blake, dispersas em várias instituições e coleções, sem alterar a sua configuração visual e literária. Fazendo referência a Benjamin, Portela argumenta que a reprodução concebida e realizada no The William Blake Archive produz o efeito de uma "aura digital", uma vez que os processos de recodificação digital restabelecem a autenticidade e a singularidade de cada exemplar ao reforçarem as diferenças materiais entre os exemplares autógrafos dos livros iluminados.

Sob o viés da crítica genética, Larissa Drigo Agostinho investiga, em "William Blake: o estudo do processo de criação de um Doppelbegabung", a natureza da relação entre os elementos verbal e imagético no livro iluminado de Blake a partir da análise do processo criativo de Songs of Innocence and of Ex- 
perience. Agostinho verifica que, embora o resultado final do livro apresente verbo e imagem integrados, quando os rascunhos correspondentes mostram as duas modalidades textuais, elas aparecem separadas. A autora conclui que o processo de criação de Blake antecipava a temática de seus poemas através de desenhos e realizava a união entre o verbal e o imagético posteriormente.

Em "Inocente experiência: pequeno diálogo com as canções de William Blake", Claudia Barbieri Masseran também explora esta relação entre palavra e imagem dos livros iluminados em sua análise de três poemas de Songs of Innocence and of Experience - "Infant Joy" e os dois poemas intitulados "Nurse's Song" -, argumentando que o texto visual amplia a interpretação do texto verbal, ressaltando ambiguidades dos estados de inocência e de experiência nos poemas.

$\mathrm{O}$ material temático e intertextual de Songs of Innocence and of Experience gera ainda a leitura de "The Sick Rose" realizada por Thais Diniz em “'A rosa doente'dos tempos modernos". Retomando o argumento de Jon Mee, que interpreta o poema como uma crítica social inspirada por um caso de corrupção política ocorrido época em que foi escrito, Diniz considera a atualidade da obra de Blake por meio de sua ressonância na instalação de David Burrows intitulada The Sick Rose.

Claudio Willer, tradutor dos poetas beats e autor de Um Obscuro Encanto - Gnose, Gnosticismo e Poesia Moderna, analisa um tema problemático na arte de Blake que diz respeito à sua dimensão mística. No século vinte, julgou-se por bem evitar a discussão inicialmente levantada por William Butler Yeats e Edwin John Ellis em sua edição das obras do autor, publicada em 1893. Willer, todavia, o reinsere numa longa tradição - não mística e sim poética - de artistas que utilizaram elementos gnósticos em seus trabalhos, analisando textos como Matrimônio de Céu e Inferno e Vala.

Enéias Tavares e Andrio Santos, por outro lado, discutem em seu artigo o impacto da obra de Blake na cultura popular do século XX e XXI, em especial no cinema, na televisão, na literatura, nas histórias em quadrinhos e na música. A partir de um referencial teórico interdisciplinar, estudam os livros iluminados do autor e suas recorrentes referências na cultura como tradução intersemiótica. Compõe o artigo um apêndice que lista muitas dessas obras, indicando possíveis percursos de análise.

Na segunda seção deste número, ampliamos a discussão sobre as relações entre literatura e outras artes para artigos que apresentam uma grande variedade de temas e perspectivas metodológicas. No primeiro, Célia de Miranda discute a montagem de Otelo, de William Shakespeare, realizada 
pelo grupo Folias D’Arte entre 2003 e 2004. Sua análise centra-se no fazer teatral enquanto procedimento imperativo, na qual elementos externos à obra dramática são utilizados a fim de fortalecer o que a autora chama de “enquadramento épico", entre outros termos discutidos em seu texto.

O próximo artigo trata do espinhoso tema da adaptação de uma obra literária para uma mídia audiovisual e os vários procedimentos tradutórios envolvidos. No texto, Helena Pereira e Luciana Dimitrov discutem a versão cinematográfica da obra A cor púrpura (1982), de Alice Walker, dirigida por Steven Spielberg em 1985. Sua análise centra-se na confluência estética e ideológica entre texto romanesco e fílmico.

Joelma Siqueira, por sua vez, parte de uma revisão histórica do problema do Ut pictura poesis, justamente entre as artes do texto e as artes da imagem, para analisar a obra narrativa de Clarice Lispector. Para a autora, importa a relação entre textos como "Romance" e "Escrever, humildade, técnica", publicados na primeira edição de A legião estrangeira (1964), tendo por contraponto a pintura moderna.

Cristiane Passafaro Guzzi discute em seu artigo a transposição de textos verbais para textos sincréticos, analisando os problemas envolvidos na relação entre literatura, cinema e televisão. Para tal discussão, analisa em especial o trabalho do diretor brasileiro Luiz Fernando Carvalho, que não raro tem recorrido a obras literárias como inspiração para projetos televisivos e cinematográficos.

Os desafios envolvidos na relação entre arte fotográfica e literária são abordados por Tatiana Prevedello. Ao analisar O arquipélago da insônia, de António Lobo Antunes (1998), a autora discute as descrições de fotografias como restauração de representações mnemónicas no discurso dos personagens. Faz isso a partir da ideia de presença na ausência, ocorrência comum em muitas passagens do romance. Seu objetivo é compreender como técnicas narrativas são usadas na ficcionalização de imagens fotográficas.

Gérson Luís Werlang apresenta o problema da música na literatura, partindo do estudo da obra de Érico Veríssimo, em especial, nos romances Saga e O Prisioneiro. Para o autor, a música tem uma forte presença como contraponto a conflitos sociais apresentados nas respectivas obras, a saber, a Guerra Civil Espanhola e a Guerra do Vietnã. Interessa ao autor os ecos referenciais que a música tem sobre a narrativa ficcional, uma constante na obra de Veríssimo.

Continuando a discussão sobre música e literatura, mas de um viés diverso, não narrativo e sim poético, Sílvio Rodrigo de Moura Rocha e 
Márcia Marques de Morais analisam a peça musical "De onde vem a canção?", do músico brasileiro Lenine. Interessa ao autor a consonância entre discurso verbal e musical, considerando a letra em sua interface com a melodia e os elementos constitutivos do plano musical da peça. A partir desta perspectiva, interpreta o cancionista como um artista/malabarista.

Juliana Bertin e Rosana Santos analisam o documentário Moscou (2009), de Eduardo Coutinho, que apresenta o processo de montagem da peça As três irmãs, de Tchekhov. A partir de uma perspectiva interdisciplinar, as autoras tratam da versão audiovisual como uma forma de recontar o texto literário, não perdendo de vista as fronteiras bem demarcadas e explicitadas no documentário entre o ficcional e o factual.

No penúltimo artigo, Martin Fletcher discute a colaboração do romancista Harold Pinter e o diretor Joseph Losey no filme The Servant, de 1963, um dos pontos altos da história do cinema britânico. A partir de uma análise da dimensão técnica da película, o autor discute problemas sociais apresentados no filme e comuns ao contexto britânico, em especial o preconceito para com as classes trabalhadoras.

Encerrando a segunda seção de artigos deste número, Fábio de Oliveira analisa quatro fotografias de Tiago Santana, publicadas em 0 chão de Graciliano, de 2006. As imagens são contrastadas com Vidas Secas (1938), de Graciliano Ramos. A partir de Barthes, o autor analisa os pictogramas utilizando os conceitos de studium e punctum, concentrando-se nas respectivas características da mídia imagética e do meio literário.

Por fim, o volume é concluído com uma resenha que aborda problemas conceituais, teóricos e artísticos apresentados neste número. Nela, Juliana Steil discute a tradução coordenada por Guilherme Gontijo Flores para o Paraíso Reconquistado, de John Milton, edição que contempla as aquarelas de William Blake para o poema.

Como ilustrado pelos comentários sobre os autores e os textos presentes neste volume de Letras, objetivamos apresentar aos leitores e leitoras uma série de percursos não apenas críticos e interpretativos como também metodológicos no que concerne à leitura e à reflexão sobre literatura e outras artes. Esperamos que a leitura desses textos possa dar origem a outras releituras e reinterpretações sobre obras e perspectivas transmídias e poéticas interartes.

Juliana Steil (UFPel)

Enéias Farias Tavares (UFSM) 
